\title{
Comment to the paper "Posterior fossa decompression and the cerebellum in Chiari type II malformation: A preliminary MRI study"
}

\author{
Mehmet Selcuki
}

Received: 6 December 2010 /Accepted: 6 December 2010/Published online: 24 December 2010

(C) Springer-Verlag 2010

Set of Chiari malformations, per se, comprise an ensemble of interesting clinical forms, which are sometimes totally different from each other in regard to the clinical symptoms and accompanying pathological conditions of the central nervous system. Embryological background and development stages still require further explanations. There is still no single treatment mode that is widely accepted. Although most of the neurosurgeons accept early surgical correction for the symptomatic cases, treatment modality for nonsymptomatic cases is still under debate. Chiari type I and type I.5 cases are totally different story $[1,2]$. The authors propose posterior fossa decompression in early infancy to prevent atrophy of cerebellum and other related posterior fossa structures in Chiari type II malformations. They calculated volumes of various structures in posterior fossa and came to a conclusion that cerebellar atrophy takes place in utero, and decompressive attempts do not help preventing cerebellar atrophy. However, they found that posterior fossa cerebrospinal fluid (CSF) volume improves and reaches to almost normal values after posterior fossa decompression as compared to normal individuals. In a recent investigation [3], total cerebellar volume was found to be significantly reduced in spina bifida myelomeningocele group as compared to the normal individuals. The results of this investigation coincide with the observations of the group, who proposes posterior fossa decompression in early infancy. The main question that suddenly rises in

\section{Selcuki $(\square)$}

Department of Neurosurgery,

Celal Bayar University, School of Medicine,

Manisa, Turkey

e-mail: mselcuki@yahoo.com the mind is, while this posterior fossa decompression relieves the structures in the posterior fossa and causes an increase in CSF volume in Chiari type II cases, could this approach has any help to hydrocephalus in these patients, which is commonly attributed to the jam at foramen magnum level. The authors have found no improvement in cerebellar atrophy after decompressive surgery. On the other hand, this investigation showed that CSF volume (space as well) is augmented by posterior fossa decompression. The aim of all decompressive surgical attempts at posterior fossa is to relieve the level of foramen magnum and provide appropriate circulation of CSF for improvement of syringomyelia and brain stem compression. Although this kind of surgical approaches need more accumulated data related to the similar cases, in order to prevent forthcoming syringomyelia, to establish appropriate CSF circulation at level of foramen magnum, and to prevent brain stem compression, which can lead to lethal complications, this procedure may be helpful for the future prognosis of the patients. After the myelomeningocele operation, the timing of the posterior fossa decompression for Chiari II patients is another question to be answered as well.

\section{References}

1. Tubbs RS, Iskandar BJ, Bartolucci AA, Oakes W (2004) A critical analysis of the Chiari 1.5 malformation. J Neurosurg 101:179-183

2. Novegno F, Caldarelli M, Massa A, Chieffo D, Massimi L, Pettorini B, Tamburrini G, Di Rocco C (2008) The natural history of the Chiari Type I anomaly. J Neurosurg Pediatr 2:179-187

3. Juranek J, Dennis M, Cirino PT, El-Messidi L, Fletcher JM (2010) The cerebellum in children with spina bifida and Chiari II malformation: quantitative volumetrics by region. Cerebellum 9:240-248. doi:10.1007/s12311-010-0157-x 